\title{
PENGARUH PENAMBAHAN AIR EKSTRAK BENGKOANG (PACHYRHIZUS EROSUS) TERHADAP MUTU PRODUK NATA DE PACHY
}

\author{
The Influence of Addition Water Extract of Yam (Pachyrhizus erosus) to Qualities for Nata \\ De Pachy \\ Deny Utomo ${ }^{1)}$;, Alfi Ro'isatul Muna ${ }^{1)}$ \\ Program Studi Ilmu dan Teknologi Pangan, Fakultas Pertanian, Universitas Yudharta Pasuruan \\ *Email: denyut369@gmail.com
}

\begin{abstract}
Nata de pachy is a diversified food that come from the tubers with Pachyrhizus erosus species commonly known as yam. Jicama is better known in the community is used as a face mask and eating meat without known that yam also contains other benefits. This study aims to determine the effect of the addition of water extract of yam proportion to the quality of nata de pachy terms of physicochemical and organoleptic. This study was a randomized block design with 2 factors, including factors fermentation time $L 1=9$ days, $L 2=11$ days, $L 3=13$ days and treatment factors using three variables, namely, $P 1=50 \%$ water extract of yam, $P 2=$ $75 \%$ water extract of yam, $P 3=100 \%$ water extract of yam $200 \mathrm{ml}$. Based on the results of physicochemical and organoleptic obtained nata de pachy that consumers preferred that L3P3 treatment (fermentation time of 13 days with the proportion of added water extract of yam 100\%: $40 \mathrm{ml}$ starter nata) with the following characteristics; the average levels of vitamin $C$ 2.89\%; texture $40.67 \mathrm{~N}$; and the average preference level panelists to taste 3; 2.2 odor; and viscosity (texture) 3.8 .
\end{abstract}

Keywords: yam, extracts, nata, processing nata.

\begin{abstract}
ABSTRAK
Nata de pachy merupakan diversifikasi bahan pangan yang berasal dari golongan umbiumbian dengan spesies Pachyrhizus erosus yang biasa dikenal dengan sebutan bengkoang. Bengkoang dalam masyarakat lebih dikenal digunakan sebagai masker wajah dan di makan dagingnya tanpa diketahui bahwasanya bengkoang juga memiliki kandungan manfaat lainnya. Penelitian ini bertujuan untuk mengetahui pengaruh proporsi penambahan air ekstrak bengkoang terhadap mutu produk nata de pachy dari segi fisiko kimia dan organoleptik. Penelitian ini menggunakan rancangan acak kelompok (RAK) dengan 2 faktor, yang meliputi faktor lama fermentasi L1= 9 hari, L2= 11 hari, L3= 13 hari dan faktor perlakuan menggunakan 3 variabel yaitu, $\mathrm{P} 1=50 \%$ air ekstrak bengkoang, $\mathrm{P} 2=75 \%$ air ekstrak bengkoang, $\mathrm{P} 3=100 \%$ air ekstrak bengkoang dari $200 \mathrm{ml}$ air ekstrak bengkoang. Berdasarkan hasil analisis fisikokimia dan organoleptik diperoleh nata de pachy yang disukai konsumen yaitu perlakuan L3P3 (lama fermentasi 13 hari dengan proporsi penambahan air ekstrak bengkoang 100\% : 40 $\mathrm{ml}$ starter nata) dengan karakteristik sebagai berikut; rata-rata kadar vitamin $\mathrm{C} 2,89 \%$; tekstur 40,67 N; serta rata-rata tingkat kesukaan panelis terhadap rasa 3; aroma 2,2; dan kekenyalan (tekstur) 3,8.
\end{abstract}

Kata kunci: bengkoang, ekstrak, nata, proses pengolahan nata. 


\section{PENDAHULUAN}

Berkembangnya varian nata yang biasanya terbuat dari air kelapa sebagai substrat dan starter, sebagai pembentuk serat-serat pada nata yang banyak dikenal dengan sebutan nata de coco. Selain Air kelapa, bengkoang yang berasal dari golongan umbi-umbian mempunyai banyak potensi yang sangat baik untuk dikembangkan, salah satunya bengkoang juga dapat menjadi salah satu substrat untuk membuat nata, yaitu dengan memanfaatkan air ekstrak bengkoang sebagai pengganti air kelapa, nata diversifikasi ini disebut dengan nata de pachy. Bengkoang dimanfaatkan karena mempunyai banyak kandungan yang dibutuhkan tubuh salah satunya kandungan inulin dan antioksidan, yang berguna untuk melancarkan pencernaan serta cocok untuk pengganti gula pada orang yang mengidap penyakit diabetes (Wardhana et al., 2016).

Penelitian tentang pembuatan nata menggunakan substrat air ekstrak bengkoang belum banyak dilakukan sehingga peneliti termotivasi untuk membuat diversifikasi olahan pangan dari bahan golongan umbi-umbian ini yaitu produk nata de pachy yang dapat memberikan kontribusi bagi para penggemar nata.

\section{METODE PENELITIAN}

\section{Bahan}

Bahan penelitian yang digunakan adalah air ekstrak bengkoang (Pachyrhizus erosus), gula, starter nata yang mengandung kultur Acetobacter xylinum, ZA food grade, asam cuka glasial $25 \%$.

\section{Rancangan percobaan}

Rancanga percobaab yang digunakan adalah Rancangan Acak Kelompok (RAK) dengan 2 faktor: Faktor 1 : Lama fermentasi yang terdiri dari 3 level L1 = 9 hari; L2 = 11 hari; $\mathrm{L} 3=13$ hari. Faktor 2 : persentase penambahan air ekstrak bengkoang yang terdiri dari 4 variabel : P1 = Penambahan air ekstrak bengkoang 50\% (100ml); P2 = Penambahan air ekstrak bengkoang $75 \%$ $(150 \mathrm{ml}) ; \mathrm{P} 3=$ Penambahan air ekstrak bengkoang $100 \%$ (200ml).

\section{Pelaksanaan Penelitian}

Proses pembuatan nata de pachy melalui 2 bagian yaitu, pembuatan air ekstrak bengkoang dan pembuatan nata de pachy.

Pembuatan air ekstrak bengkoang diawali dengan menyiapkan bahan (bengkoang), setelah itu dilakukan pengelupasan kulit luar bengkoang karena dalam penelitian ini yang dibutuhkan hanya daging putih bengkoang. Setelah itu, daging bengkoang dicuci hingga bersih, selanjutnya dilakukan penimbangan $(1 \mathrm{~kg})$ setelah penimbangan dilakukan proses pemarutan untuk memudahkan mengambil air ekstrak bengkoang dengan ditambah 1Liter air. Setelah itu, dilakukan proses penyaringan menggunakan penyaring dan diperoleh air ekstrak bengkoang.

Pembuatan nata de pachy dengan penyiapan bahan baku berupa gula, ZA, starter acetobacter xylinum, asam cuka glasial 25\% serta penyiapan air ekstrak bengkoang yang sudah di endapkan 1-2 jam, dengan pembagian sebagai berikut:

$\mathrm{P} 1=50 \%$ dari $200 \mathrm{ml}(100 \mathrm{ml})$

$\mathrm{P} 2=75 \%$ dari $200 \mathrm{ml}(150 \mathrm{ml})$

P3 $=100 \%$ dari $200 \mathrm{ml}(200 \mathrm{ml})$

Dan dicampurkan dengan gula (50 gr), ZA (3 gr), asam cuka glasial 25\% (20 ml) dan starter $(40 \mathrm{ml})$. setelah bahan baku dipanaskan dituang dalam wadah plastik yang sudah disiapkan dan sesuai dengan pembagian diatas. Wadah plastik ditutup menggunakan Koran dan karet gelang sebagai pengikatnya.

\section{Pengamatan}

Pengamatan yang dilakukan meliputi uji fisikokimia dan organoleptik. Analisa fisikokimia meliputi kadar vitamin $\mathrm{C}$ dan tekstur. Sedangkan, sifat organoleptik meliputi warna, rasa, tekstur (kekenyalan) dan aroma terhadap kesukaan (hedonic) skor 
menggunakan 20 orang panelis dari kategori tidak terlatih.

\section{Analisa data}

Data dari pengamatan analisa uji fisiko kimia dilakukan analisa ragam ANOVA dengan selang kepercayaan 5\% dan $1 \%$. Apabila ditemukan pengaruh terhadap salah satu variabel maka dilanjutkan dengan uji Beda Nyata Terkecil (BNT) dengan selang kepercayaan $1 \%$. Untuk uji organoleptik menggunakan uji Friedman. Perlakuan terbaik menggunakan metode indeks efektifitas de Garmo et al., (1984) yang termodifikasi oleh Susrini (2005).

\section{HASIL DAN PEMBAHASAN}

\section{Vitamin C}

Berdasarkan hasil analisis kadar vitamin C dalam air ekstrak bengkoang (Pachyrhizus erosus) diperoleh rata-rata kadar vitamin C 1,40\% sampai dengan $2,89 \%$. Seperti dalam gambar 1 .
Dalam gambar diatas menyatakan bahwa perlakuan L3P3 (lama fermentasi 13 hari dengan penambahan air ekstrak bengkoang $100 \% \quad(200 \mathrm{ml}$ air ekstrak bengkoang) : $40 \mathrm{ml}$ starter nata de pachy) memiliki nilai rata-rata kadar vitamin $\mathrm{C}$ dengan prosentase tertinggi yaitu 2,89\%. Dapat diketahui bahwasanya proporsi penambahan air ekstrak bengkoang sangat berpengaruh pada kadar vitamin $\mathrm{C}$ dalam nata de pachy, seperti dalam gambar 4.1, semakin bertambah proporsi penambahan air ekstrak bengkoang, maka semakin tinggi pula kadar vitamin $\mathrm{C}$ yang terkandung dalam nata de pachy. Semakin lama fermentasi juga berpengaruh pada meningkatnya kadar vitamin $\mathrm{C}$..

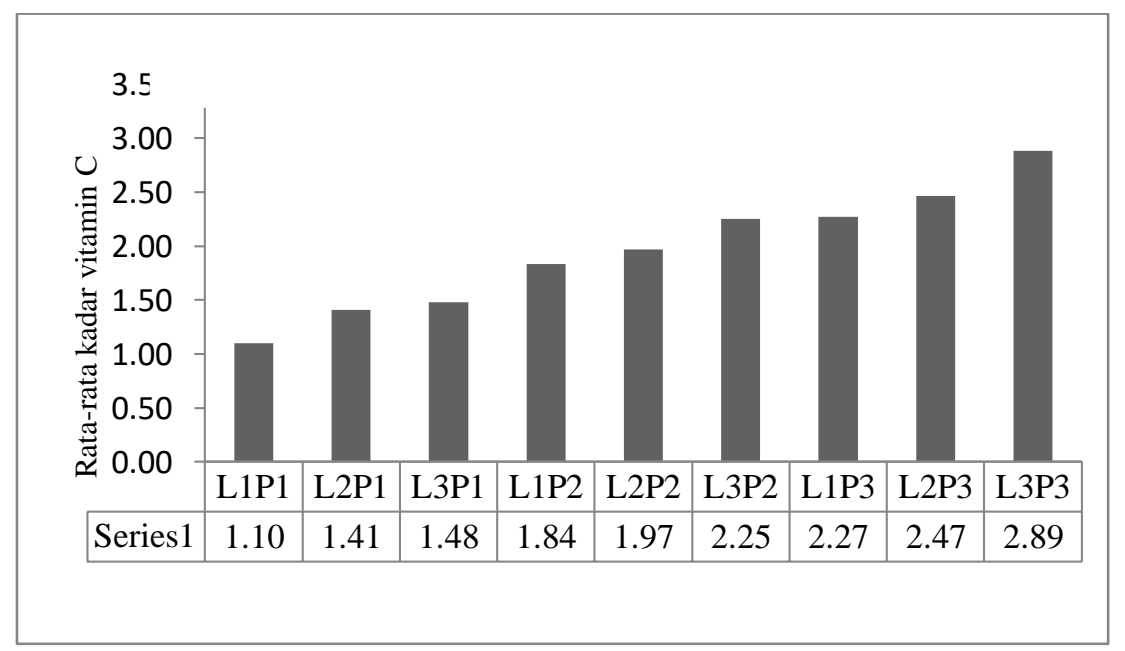

Keterangan :

L1P1 = lama fermentasi 9 hari dan ekstrak bengkoang 50\%, L2P1 = lama fermentasi 11 hari dan ekstrak bengkoang 50\%, L3P1= lama fermentasi 13 dan ekstrak bengkoang 50\%, L1P2= lama fermentasi 9 hari dan ekstrak bengkoang 75\%, L2P2= lama fermentasi 11 hari dan ekstrak bengkoang 75\%, L3P2= lama fermentasi 13 hari dan ekstrak bengkoang 75\%, L1P3= lama fermentasi 9 hari dan ekstrak bengkoang 100\%, L2P3= lama fermentasi 11 hari dan ekstrak bengkoang 100\%, L3P3= lama fermentasi 13 hari dan ekstrak bengkoang 100\%.

Gambar 1. Rata-rata kadar vitamin C pada Nata de pachy 


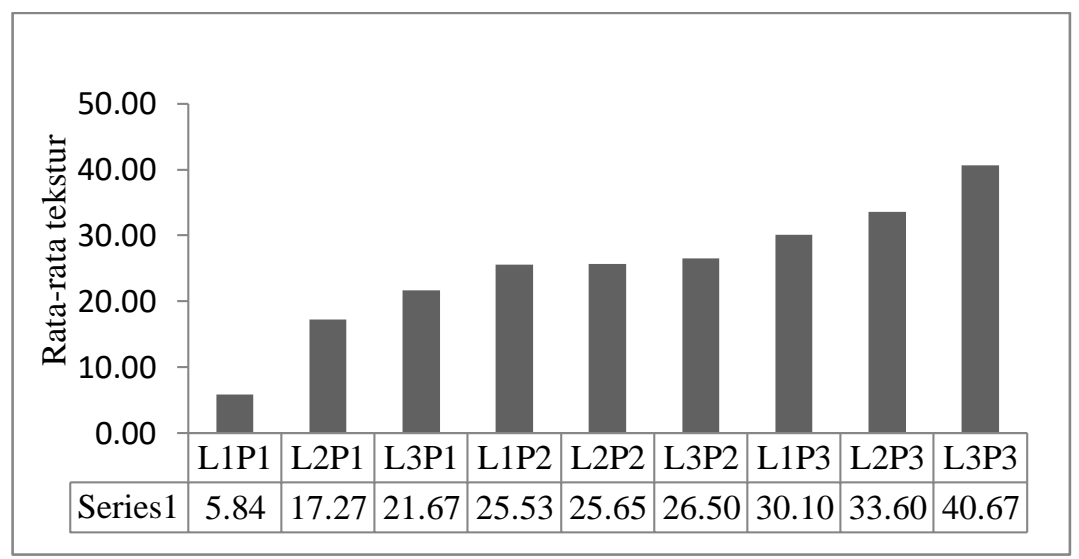

Keterangan :

L1P1 = lama fermentasi 9 hari dan ekstrak bengkoang 50\%, L2P1 = lama fermentasi 11 hari dan ekstrak bengkoang 50\%, L3P1= lama fermentasi 13 dan ekstrak bengkoang 50\%, L1P2= lama fermentasi 9 hari dan ekstrak bengkoang 75\%, L2P2= lama fermentasi 11 hari dan ekstrak bengkoang 75\%, L3P2= lama fermentasi 13 hari dan ekstrak bengkoang 75\%, L1P3= lama fermentasi 9 hari dan ekstrak bengkoang 100\%, L2P3= lama fermentasi 11 hari dan ekstrak bengkoang 100\%, L3P3= lama fermentasi 13 hari dan ekstrak bengkoang $100 \%$.

Gambar 2. Rata-rata hasil uji fisiko kimia tekstur pada Nata de pachy

\section{Tekstur}

Berdasarkan hasil uji fisik tekstur nata de pachy memiliki nilai rata-rata 5,84 N sampai dengan 40,67 N. Seperti dalam gambar. 2. Dalam gambar, dapat disimpulkan bahwa yang memiliki nilai ratarata terendah yaitu L1P1 (lama fermentasi 9 hari dengan proporsi pe-nambahan air ekstrak 50\% (100 ml air ekstrak bengkoang) : $40 \mathrm{ml}$ starter nata) dengan nilai rata-rata
5,84 N. Sedangkan untuk nilai rata-rata tertinggi pada perlakuan L3P3 (lama fermentasi 13 hari dengan proporsi penambahan air ekstrak bengkoang $100 \%$ (200 ml air ekstrak bengkoang) : $40 \mathrm{ml}$ starter nata) dengan nilai rata-rata 40,67 N. Dalam hal ini semakin tinggi proporsi penambahan air ekstrak bengkoang, maka semakin tebal dan semakin baik tekstur yang dimiliki oleh nata de pachy.

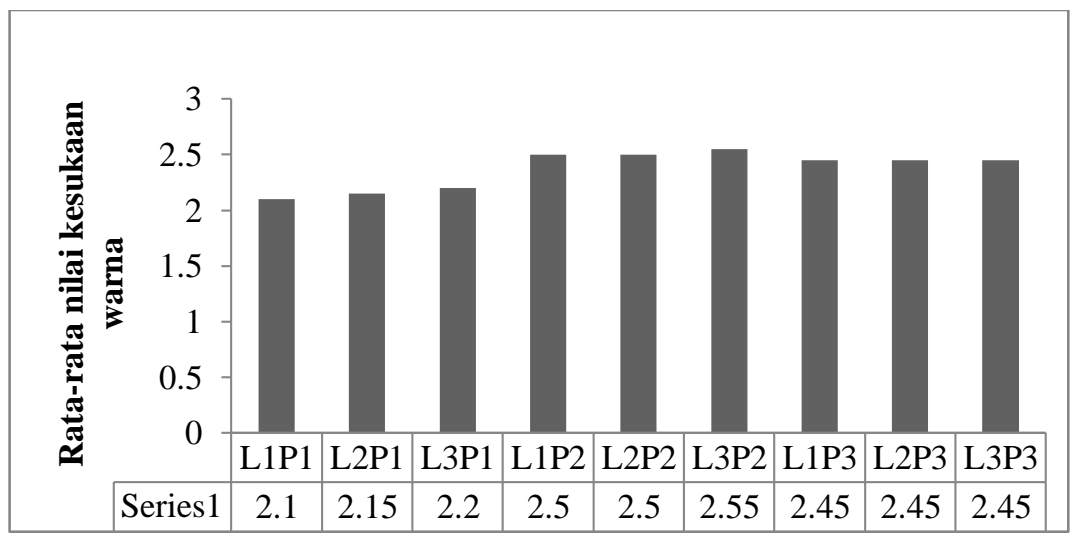

Keterangan :

L1P1 = lama fermentasi 9 hari dan ekstrak bengkoang 50\%, L2P1 = lama fermentasi 11 hari dan ekstrak bengkoang 50\%, L3P1= lama fermentasi 13 dan ekstrak bengkoang 50\%, L1P2= lama fermentasi 9 hari dan ekstrak bengkoang 75\%, L2P2= lama fermentasi 11 hari dan ekstrak bengkoang 75\%, L3P2= lama fermentasi 13 hari dan ekstrak bengkoang 75\%, L1P3= lama fermentasi 9 hari dan ekstrak bengkoang 100\%, L2P3= lama fermentasi 11 hari dan ekstrak bengkoang 100\%, L3P3= lama fermentasi 13 hari dan ekstrak bengkoang $100 \%$.

Gambar 3. Rata-rata organoleptik warna pada Nata de pachy 
Gambar 3 memperlihatkan rata-rata nilai kesukaan panelis terhadap warna pada nata de pachy yang mempunyai persentase terendah yaitu L1P1 (lama fermentasi 9 hari dengan penambahan air ekstrak bengkoang 50\% (100 ml air ekstrak bengkoang) : $40 \mathrm{ml}$ starter nata) dengan nilai kesukaan 2.1, L2P1 (lama fermentasi 11 hari dengan penambahan air ekstrak bengkoang 50\% (100 ml air ekstrak bengkoang) : $40 \mathrm{ml}$ starter nata) dengan nilai kesukaan 2,15, L3P1 (lama fermentasi 13 hari dengan penambahan air ekstrak bengkoang 50\% (100 ml air ekstrak bengkoang) : $40 \mathrm{ml}$ starter nata) dengan nilai kesukaan sebesar 2,2, sedangkan rata-rata nilai kesukaan panelis terhadap warna pada nata de pachy yang mempunyai persentase tertinggi yaitu L3P2 (lama fermentasi 13 hari dengan penambahan air ekstrak bengkoang $75 \%$ (150 ml air ekstrak bengkoang) : $40 \mathrm{ml}$ starter nata dengan nilai kesukaan sebesar 2,55 yang berarti menyukai. Dari hasil pengamatan dapat disimpulkan bahwa semakin tinggi persentase proporsi penambahan air ekstrak bengkoang maka warna pada nata de pachy yang dihasilkan semakin disukai oleh panelis.

\section{Rasa}

Semakin tinggi nilai kesukaan panelis pada rasa nata de pachy, maka semakin tinggi pula tingkat rasa yang disukai oleh panelis. Rata-rata nilai kesukaan panelis terhadap rasa pada nata de pachy dapat dilihat pada gambar 3. Gambar 3 memperlihatkan rata-rata nilai kesukaan panelis terhadap rasa nata de pachy yang mempunyai nilai terendah yaitu, L1P1 (lama fermentasi 9 hari dengan penambahan air ekstrak bengkoang 50\% (100 ml air ekstrak bengkoang) : $40 \mathrm{ml}$ starter nata) dengan nilai kesukaan 1,55, L2P1 (lama fermentasi 11 hari dengan penambahan air ekstrak bengkoang $50 \% \quad(100 \mathrm{ml}$ air ekstrak bengkoang) : $40 \mathrm{ml}$ starter nata) 1,65, L3P1 (lama fermentasi 13 hari dengan penambahan air ekstrak bengkoang 50\% (100 $\mathrm{ml}$ air ekstrak bengkoang) : $40 \mathrm{ml}$ starter nata) dengan nilai yaitu 1,65 , sedangkan rata-rata nilai kesukaan rasa pada nata de pachy yang mempunyai persentase tertinggi yaitu, L1P3 (lama fermentasi 9 hari dengan penambahan air ekstrak bengkoang $100 \%$ (200 ml air ekstrak bengkoang) : $40 \mathrm{ml}$ starter nata), L2P3 (lama fermentasi 11 hari dengan penambahan air ekstrak bengkoang 100\% (200 ml air ekstrak bengkoang) : 40 ml starter nata), L3P3 (lama fermentasi 13 hari dengan penambahan air ekstrak bengkoang $100 \% \quad(200 \mathrm{ml}$ air ekstrak bengkoang) : $40 \mathrm{ml}$ starter nata) dengan nilai kesukaan sebesar 3. Dari hasil pengamatan dapat disimpulkan bahwa semakin tinggi persentase proporsi penambahan air ekstrak bengkoang maka rasa pada nata de pachy yang dihasilkan semakin disukai oleh panelis. 


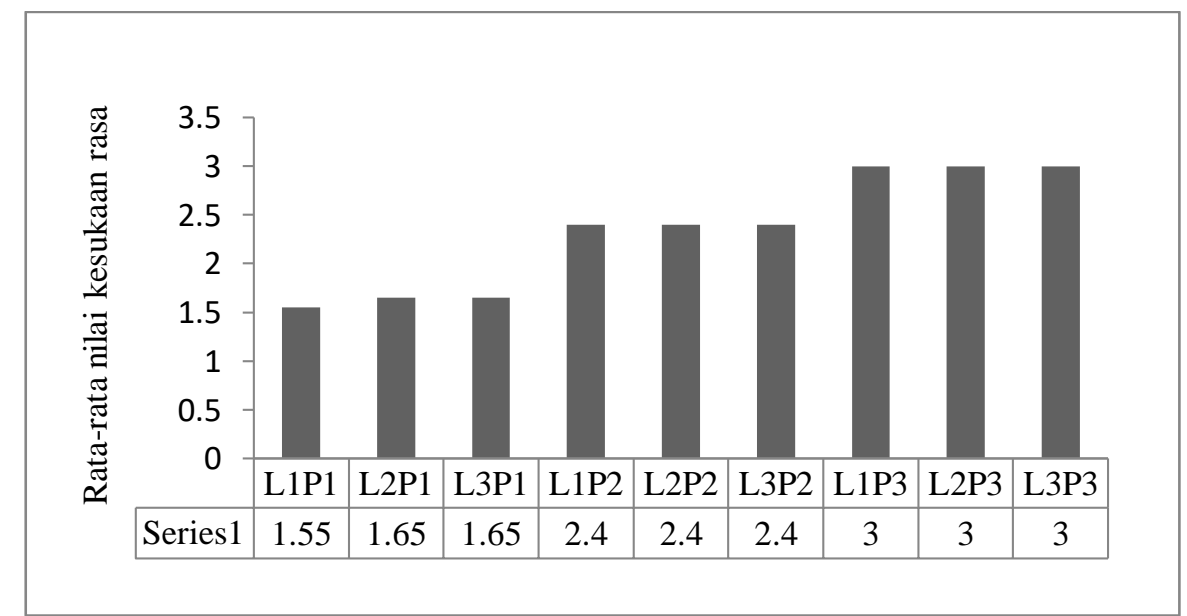

Keterangan :

L1P1 = lama fermentasi 9 hari dan ekstrak bengkoang 50\%, L2P1 = lama fermentasi 11 hari dan ekstrak bengkoang 50\%, L3P1= lama fermentasi 13 dan ekstrak bengkoang 50\%, L1P2= lama fermentasi 9 hari dan ekstrak bengkoang 75\%, L2P2= lama fermentasi 11 hari dan ekstrak bengkoang 75\%, L3P2= lama fermentasi 13 hari dan ekstrak bengkoang 75\%, L1P3= lama fermentasi 9 hari dan ekstrak bengkoang 100\%, L2P3= lama fermentasi 11 hari dan ekstrak bengkoang $100 \%$, L3P3= lama fermentasi 13 hari dan ekstrak bengkoang $100 \%$.

Gambar 4. Rata-rata organoleptik rasa pada Nata de pachy

\section{Aroma}

Gambar memperlihatkan rata-rata nilai kesukaan panelis terhadap aroma pada nata de pachy yang mempunyai persentase terendah yaitu, L1P1 (lama fermentasi 9 hari dengan penambahan air ekstrak 50\% (100 $\mathrm{ml}$ air ekstrak bengkoang) : $40 \mathrm{ml}$ starter nata), L2P1 (lama fermentasi 11 hari dengan penambahan air ekstrak bengkoang 50\% (100 ml air ekstrak bengkoang) : $40 \mathrm{ml}$ air ekstrak bengkoang), L3P1 (lama fermentasi 13 hari dengan penambahan air ekstrak bengkoang $50 \%(100 \mathrm{ml}$ air ekstrak bengkoang) : $40 \mathrm{ml}$ starter nata) dengan nilai yaitu sebesar 2,1, sedangkan untuk rata-rata nilai kesukaan terhadap aroma pada nata de pachy yang memiliki persentase tertinggi yaitu, L1P3 (lama fermentasi 9 hari dengan penambahan air ekstrak bengkoang 100\% (200 ml air ekstrak bengkoang) : 40 $\mathrm{ml}$ starter nata), L2P3 (lama fermentasi 11 hari dengan penambahan air ekstrak bengkoang $100 \% \quad(200 \mathrm{ml}$ air ekstrak bengkoang) : $40 \mathrm{ml}$ starter nata), L3P3 (lama fermentasi 13 hari dengan penambahan air ekstrak 100\% (200 ml air ekstrak bengkoang) : $40 \mathrm{ml}$ starter nata) yang masing-masing memiliki nilai tertinggi sebesar 2,2 yang berarti menyukai.

Dari hasil pengamatan dapat disimpulkan bahwa semakin tinggi penambahan air ekstrak bengkoang, maka aroma pada nata de pachy yang dihasilkan semakin disukai oleh panelis. Akan tetapi, untuk menghilangkan aroma asam pada nata de pachy, sebaiknya dilakukan perebusan hingga $2 \mathrm{x}$ dan penggantian air secara berkala saat penyimpanan nata untuk menghindari aroma asam dan ketengikan pada nata de pachy. 


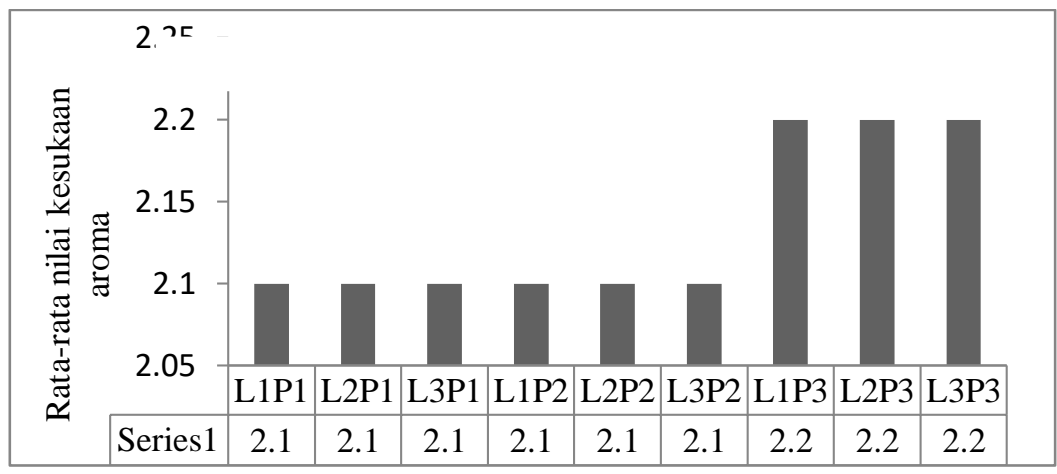

Keterangan :

L1P1 = lama fermentasi 9 hari dan ekstrak bengkoang 50\%, L2P1 = lama fermentasi 11 hari dan ekstrak bengkoang 50\%, L3P1= lama fermentasi 13 dan ekstrak bengkoang 50\%, L1P2= lama fermentasi 9 hari dan ekstrak bengkoang 75\%, L2P2= lama fermentasi 11 hari dan ekstrak bengkoang $75 \%, \mathrm{~L} 3 \mathrm{P} 2=$ lama fermentasi 13 hari dan ekstrak bengkoang 75\%, L1P3= lama fermentasi 9 hari dan ekstrak bengkoang 100\%, L2P3= lama fermentasi 11 hari dan ekstrak bengkoang 100\%, L3P3= lama fermentasi 13 hari dan ekstrak bengkoang 100\%.

Gambar 5. Rata-rata organoleptik aroma Nata de pachy

\section{Kekenyalan}

Gambar memperlihatkan rata-rata nilai kesukaan panelis terhadap tekstur (kekenyalan) pada produk nata de pachy yang mempunyai persentase terendah yaitu L1P1 (lama fermentasi 9 hari dengan penambahan air ekstrak bengkoang 50\% (100 ml air ekstrak bengkoang) : $40 \mathrm{ml}$ starter nata) dengan nilai kesukaan 1,25, L2P1 (lama fermentasi 11 hari dengan penambahan air ekstrak bengkoang 50\% (100 ml air ekstrak bengkoang) : $40 \mathrm{ml}$ starter nata) dengan nilai kesukaan 1,75, L3P1 (lama fermentasi 13 hari dengan penambahan air ekstrak bengkoang 50\% (100 ml air ekstrak bengkoang) : $40 \mathrm{ml}$ starter nata) dengan persentase nilai 2,1, sedangkan rata-rata nilai kesukaan tertinggi terhadap kekenyalan yaitu L2P3 (lama fermentasi 11 hari dengan penambahan air ekstrak bengkoang $100 \%(200 \mathrm{ml}$ air ekstrak bengkoang) : $40 \mathrm{ml}$ starter nata), L3P3 (lama fermentasi 13 hari penambahan air ekstrak bengkoang 100\% (200 ml air ekstrak bengkoang) : $40 \mathrm{ml}$ starter nata) dengan persentase nilai tertinggi sebesar 3,8 yang berarti sangat menyukai .

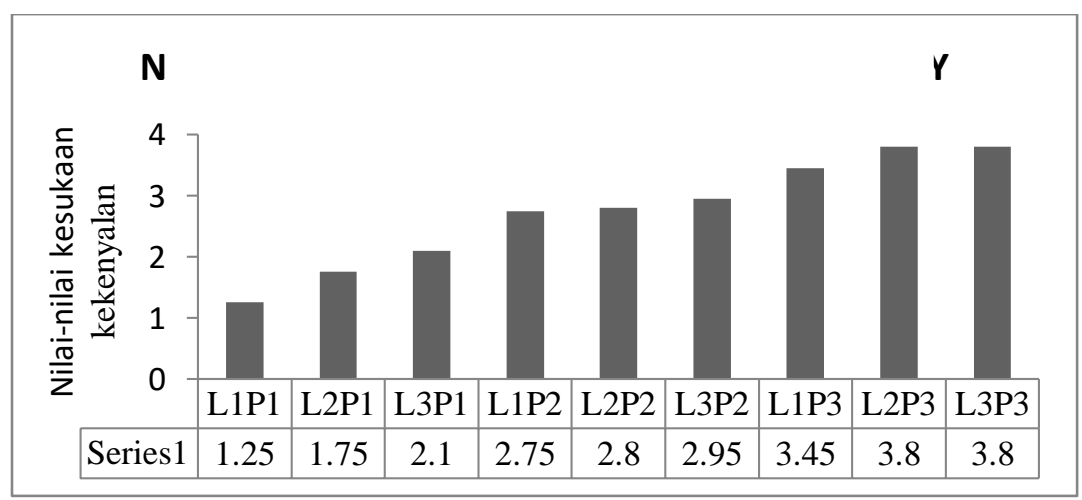

Keterangan :

L1P1 = lama fermentasi 9 hari dan ekstrak bengkoang 50\%, L2P1 = lama fermentasi 11 hari dan ekstrak bengkoang 50\%, L3P1= lama fermentasi 13 dan ekstrak bengkoang 50\%, L1P2= lama fermentasi 9 hari dan ekstrak bengkoang 75\%, L2P2= lama fermentasi 11 hari dan ekstrak bengkoang 75\%, L3P2= lama fermentasi 13 hari dan ekstrak bengkoang 75\%, L1P3= lama fermentasi 9 hari dan ekstrak bengkoang 100\%, L2P3= lama fermentasi 11 hari dan ekstrak bengkoang 100\%, L3P3= lama fermentasi 13 hari dan ekstrak bengkoang $100 \%$.

Gambar 6. Rata-rata organoleptik kekenyalan pada Nata de pachy 
Tabel 1. Uji Indeks Efektifitas

\begin{tabular}{lc}
\hline \multicolumn{1}{c}{ Perlakuan } & Rata-rata \\
\hline L1P1 (lama fermentasi 9 hari, air ekstrak 100ml) & 0,17 \\
L2P1 (lama fermentasi 11 hari, air ekstrak 100ml) & 0,34 \\
L3P1 (lama fermentasi 13 hari, air ekstrak 100ml) & 0,31 \\
L1P2 (lama fermentasi 9 hari, air ekstrak 150ml) & 0,64 \\
L2P2 (lama fermentasi 11 hari, air ekstrak 150ml) & 0,50 \\
L3P2 (lama fermentasi 13 hari, air ekstrak 150ml) & 0,61 \\
L1P3 (lama fermentasi 9 hari, air ekstrak 200ml) & $0,71^{* 3}$ \\
L2P3 (lama fermentasi 11 hari, air ekstrak 200ml) & $0,76^{* 2}$ \\
L3P3 (lama fermentasi 13 hari, air ekstrak 200ml) & $0,97^{* 1}$
\end{tabular}

Keterangan : ${ }^{* 1}$ : terbaik $1,{ }^{* 2}$ : terbaik $2,{ }^{* 3}$ : terbaik 3 .

Dari hasil pengamatan dapat disimpulkan bahwa semakin tinggi persentase nilai kekenyalan pada nata de pachy, maka semakin tinggi pula kesukaan panelis terhadap kekenyalan pada nata de pachy. Hal ini dikarenakan semakin banyak pula persentase proporsi penambahan air ekstrak bengkoang akan menghasilkan nata dengan kekenyalan yang baik.

\section{Uji Indeks Efektifitas}

Penentuan perlakuan terbaik pada nata de pachy dilakukan dengan menggunakan metode indeks efektifitas (De Garmo, 1984) yang dimodifikasi oleh Susrini (2003). Metode ini dilakukan pada parameter kimiawi meliputi uji vitamin $\mathrm{C}$ dan tekstur, serta uji fisik yang meliputi warna, rasa, aroma dan kekenyalan.

Hasil perhitungan menunjukkan perlakuan terbaik terdapat pada perlakuan L3P3 (lama fermentasi 13 hari, air ekstrak 200ml) dengan ketentuan rata-rata fisiko kimia vitamin $\mathrm{C} 0,17 \%$; tekstur $0,23 \mathrm{~N}$, dan rata-rata uji organoleptik warna 0,10 ; aroma 0,1 ; rasa 0,15 ; kekenyalan 0,21 ; serta ratarata tingkat kesukaan panelis terhadap warna 2,55; rasa 3; aroma 2,2; kekenyalan 3,8 .

\section{KESIMPULAN DAN SARAN}

\section{Kesimpulan}

Berdasarkan hasil penelitian didapatkan bahwa antara proporsi penambahan air ekstrak bengkoang terhadap produk nata de pachy berpengaruh nyata terhadap kadar vitamin $\mathrm{C}$, tekstur, serta organoleptik warna, rasa, aroma, tekstur (kekenyalan), Berdasarkan hasil penelitian didapatkan perlakuan terbaik dalam proporsi penambahan air ekstrak bengkoang 100\% dengan karakteristik sebagai berikut; ratarata kadar vitamin C 2,89\%; tekstur 40,67 $\mathrm{N}$; serta rata-rata tingkat kesukaan panelis terhadap rasa 3; aroma 2,2; dan kekenyalan (tekstur) 3,8.

\section{Saran}

Perlu dilakukan penelitian lanjutan dengan menggunakan proporsi penambahan dengan menggunakan air ekstrak bengkoang yang lebih banyak \pm 1 liter, agar bisa mendapatkan hasil yang lebih baik. Perlu dilakukan penelitian lanjutan kajian masa simpan produk nata de pachy agar tidak tengik dan mempunyai mutu yang baik selama penyimpanan. 


\section{DAFTAR PUSTAKA}

De Garmo., Sullevan WE., CR Canana. 1984. Engineering Economis. New York, Ed. Macmilland Publ. Co.

Susrini. 2003. Indeks Efektifitas. Fakultas Peternakan Universitas Brawijaya. Malang.

Wardhana, E., Rusmarilin, H., Yusraini, E. 2016. Pengaruh Konsentrasi Gula dan pH Terhadap Mutu Nata De Yammy dari Limbah Cair Pati Bengkoang. Jurnal Rekayasa Pangan 